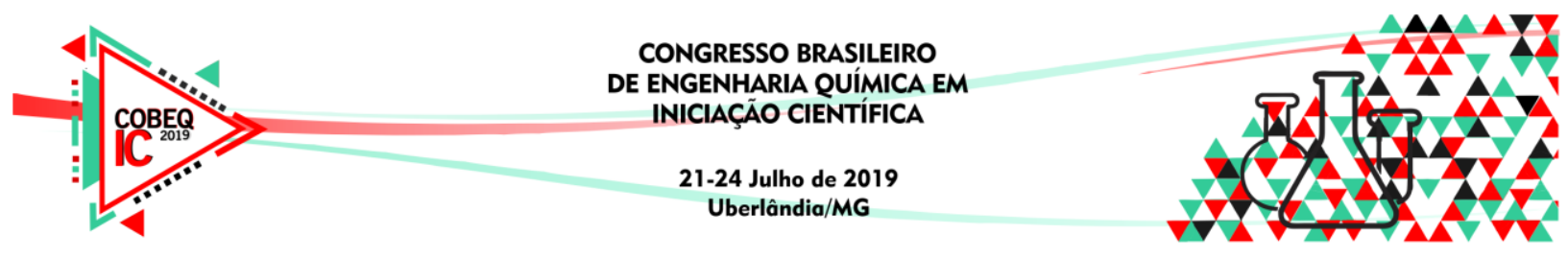

\title{
EQUILÍBRIO LÍQUIDO-LÍQUIDO DE SISTEMAS FORMADOS POR LI + ACETONA + ÁGUA A $20^{\circ} \mathrm{C}$.
}

\author{
G. C. A. NETTO ${ }^{1}$, F. B. S. HOBI ${ }^{1}$, R. M. DIAS ${ }^{1}$, F. P. PELAQUIM ${ }^{1}$, M. C. $\operatorname{COSTA}^{1}$ \\ ${ }^{1}$ Departamento de Desenvolvimento de Processos e Produtos, Faculdade de Engenharia \\ Química, Universidade Estadual de Campinas, Campinas, SP, Brasil \\ *E-mail para contato: giovana.can@gmail.com
}

\begin{abstract}
RESUMO - Líquidos iônicos são sais geralmente líquidos à temperatura ambiente, que possuem diferentes propriedades dependendo dos íons que os constituem. Dessa forma, eles podem ser utilizados em uma vasta gama de aplicações, inclusive como solventes. Neste trabalho, foram avaliados dados de equilíbrio líquido-líquido para os sistemas formados por HDEAPr+ água+ acetona e HEAPr + água + acetona a $20{ }^{\circ} \mathrm{C}$. Optou-se por trabalhar com líquidos iônicos próticos, pois eles são de fácil síntese, possuem baixo custo e são biodegradáveis. Para cada sistema foi construída a curva binodal, utilizando a metodologia do ponto de névoa, e determinadas linhas de amarração, utilizando o método gravimétrico. Os dados de equilíbrio dos dois sistemas ficaram próximos entre si e comprovaram que podem ser aplicados em processos de separação uma vez que há a formação de uma região bifásica.
\end{abstract}

\section{INTRODUÇÃO}

Líquidos iônicos (LIs) são uma classe de solventes que está sendo muito estudada. Os LIs são sais costumeiramente líquidos à temperatura ambiente e consistem inteiramente em espécies iônicas (Earle; Seddon, 2000). Como eles são formados por, no mínimo, dois componentes (um doador e um receptor de hidrogênio) variados, eles podem ter características que atendam a um uso particular ou que tenham um conjunto particular de propriedades. É por esse motivo que são conhecidos como solventes design. Propriedades como ponto de fusão, viscosidade, densidade, hidrofobicidade e miscibilidade em água dos LIs são alteradas dependendo da estrutura dos íons formadores do sal (Earle; Seddon, 2000).

Os líquidos iônicos incorporam cátions que podem ser criados através da adição de um $\mathrm{H}^{+}$ou $\mathrm{R}^{+}$ao par de um heteroátomo isolado, que é parte integrante da estrutura molecular do cátion incipiente (Mirjafari et al., 2013). Os líquidos iônicos provenientes da adição de $\mathrm{H}^{+}$são chamados de líquidos iônicos "próticos" (LIPs), e os decorrentes da adição de $\mathrm{R}^{+}$são denominados "apróticos" (LIAs) (Macfarlane; Seddon, 2007). Os LIPs têm atraído grande atenção por serem biodegradáveis, formarem fortes ligações de hidrogênio, serem facilmente sintetizados e por ter menor custo em comparação aos LIAs - e por esses motivos serão o enfoque deste trabalho.

Uma aplicação na qual é possível a utilização dos LIs é no processo de extração líquidolíquido utilizando sistemas aquosos bifásicos (ATPS), nos quais as moléculas de interesse 


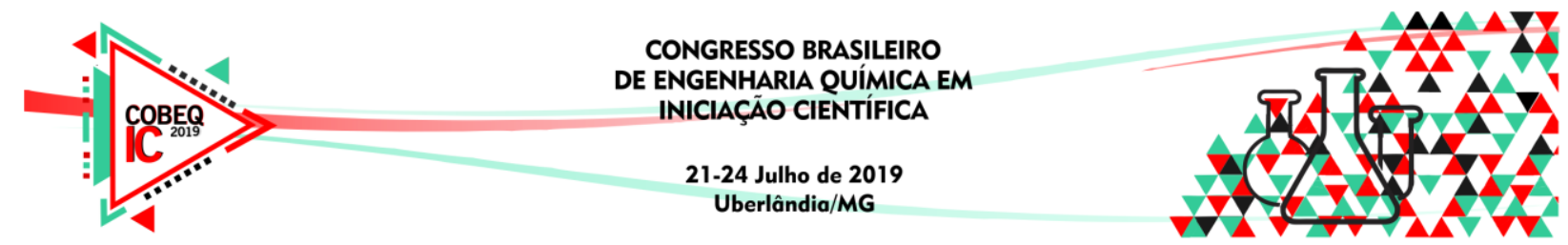

particionam-se entre as fases do sistema heterogêneo devido à diferença de afinidade. Esse tipo de sistema é muito empregado para determinação do coeficiente de partição e, dependendo do valor deste coeficiente, pode-se fazer a extração e purificação de diversos compostos. Acredita-se que a os ATPs poderão ser facilmente utilizados em processos contínuos e industriais devido à sua facilidade de dimensionamento, reciclabilidade, rapidez e segurança ambiental (Naganagouda; Mulimani, 2008).

Considerando todas as propriedades dos LIPs apresentadas, eles são bons candidatos para os processos de separação de compostos de alto valor agregado, uma vez que são considerados solventes sustentáveis e seletivos. Desta forma, neste trabalho foi estudado o equilíbrio líquido-líquido de dois ATPS - um formado por HDEAPr + água + acetona e outro, por HEAPr + água + acetona a $20{ }^{\circ} \mathrm{C}$. Ambos os líquidos iônicos têm como precursor o ácido propiônico e, as bases utilizadas foram a dietanolamina e a monoetanolamina, respectivamente.

\section{MATERIAIS E MÉTODOS}

\subsection{Materiais}

Utilizou-se acetona comprada da Anidrol, com pureza de 99,5\%. O ácido propiônico e a monoetanolamina, ambos com pureza de $99 \%$ foram obtidos da Merck e usados para preparar o HEAPr. Já a dietanolamina com pureza de $99 \%$ usada para preparar o HDEAPr foi adquirida da Dinâmica. Ambos os LIPs foram preparados conforme a metodologia descrita por Àlvarez et al. (2010) e, após sua síntese, foram rotaevaporados para redução do teor de umidade.

\subsection{Métodos}

Síntese dos líquidos iônicos: O reagente básico utilizado foi inserido em um balão volumétrico de fundo redondo com 3 bocas paralelas. A ele foi acoplado um condensador para refluxo do vapor, já que a reação de neutralização é exotérmica; um funil de decantação com gotejador e um termopar PT-100, para controle de temperatura. Todo o conjunto foi colocado dentro de um recipiente com gelo para garantir a temperatura em torno de $10{ }^{\circ} \mathrm{C}$, e essa montagem foi colocada sob uma chapa de agitação magnética. $\mathrm{O}$ reagente ácido foi adicionado à base, gota a gota, enquanto manteve-se constante a agitação do sistema. A mistura ocorreu por 24 horas. Este procedimento foi baseado no encontrado em Àlvarez et al. (2010).

Como a concentração do líquido iônico é um parâmetro importante de controle para as próximas metodologias, o próximo passo consistiu em transferir a solução de LI preparada para um rotaevaporador, conectado a uma bomba de vácuo que opera com agitação vigorosa e aquecimento em torno de $50{ }^{\circ} \mathrm{C}$. Com isso, objetivou-se chegar a uma baixa concentração de líquido iônico, em torno de $3 \%$ no máximo.

Curva binodal: Foram preparadas uma solução aquosa de acetona e outra de HDEAPr com concentrações mássicas definidas. A solução de acetona foi colocada em uma célula de 


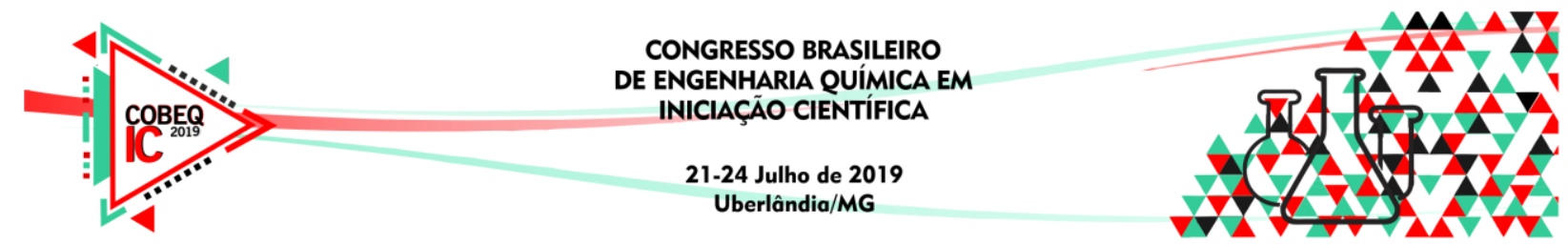

equilíbrio bem vedada (para evitar a perda da acetona, substância muito volátil) e a célula foi conectada a um banho ultratermostático para manutenção da temperatura em $20{ }^{\circ} \mathrm{C}$. O HDEAPr foi gotejado à solução de acetona com auxílio de uma seringa até que houvesse a turvação do sistema. A solução remanescente de LI foi pesada, obtendo-se a massa deste sal utilizada para atingir o ponto de névoa. Prosseguiu-se com a adição de água ao sistema para desfazer a turvação e sua massa também foi determinada. Esses passos foram repetidos até se ter pontos suficientes para a construção da curva binodal. O mesmo procedimento foi realizado substituindo o HDEAPr por HEAPr (Kaul, 2000).

As curvas binodais foram ajustadas de acordo com a equação de Merchuck et. al (1998), equação 1, na qual A, B e C são parâmetros ajustáveis, X é a concentração mássica de acetona e Y a concentração mássica de líquido iônico.

$$
Y_{\text {mod }}=A \cdot \exp \left[\left(B X^{, 05}\right)-\left(C X^{3}\right)\right]
$$

Linhas de amarração: Para a determinação das linhas de amarração (LAs) de cada sistema foi empregado o método gravimétrico descrito por Merchuck et al. (1998). Foram escolhidos 6 pontos na região bifásica e as soluções foram preparadas em um tubo centrífuga e agitadas em um Vórtex até a completa dissolução dos compostos. As soluções foram levadas para um banho e ficaram imersas em água a $20^{\circ} \mathrm{C}$ por 24 horas, garantindo assim o equilíbrio de fases. Após esse período, a fase de topo foi separada, com o auxílio de uma pipeta Pasteur, e pesada. A massa da fase de fundo foi calculada por diferença. Utilizando as equações do método de Merchuck, foi possível calcular a composição de cada fase e a inclinação das linhas de amarração (ILA) (equação 2).

$$
I L A=\left(\frac{Y_{T}-Y_{B}}{x_{T}-X_{B}}\right)
$$

Ajuste de parâmetros de interação binária para o modelo NRTL: Em nível molecular, estabelece-se que o comportamento de soluções líquidas baseia-se na teoria da composição local, que estabelece que a composição do sistema nas vizinhanças de uma molécula difere da composição bulk devido às forças intermoleculares. Esse conceito norteou alguns modelos termodinâmicos, com destaque ao Non-Random Two-Liquid, proposto em 1968 por Renon\&Prausnitz. Este modelo tem grande aplicabilidade a vários sistemas mas implica que os dados experimentais tenham grande precisão devido à existência de três modelos a serem ajustados.

Calcularam-se os parâmetros de interação binária através do método Simplex (Nelder, 1965) e do princípio da máxima verossimilhança, utilizando-se o código Fortran TML-LLE (Stragevitch, 1997), minimizando a função objetivo descrita na equação 3.

$$
F O=\sum_{k}^{D} \sum_{j}^{M} \sum_{i}^{N-1}\left(w_{i j k}^{I \cdot \exp }-w_{i j k}^{I \cdot \text { collc }}\right)^{2}+\left(w_{i j k}^{I I \cdot \exp }-w_{i j k}^{I I . \cdot c a l c}\right)^{2}
$$

Em que $D$ é o número de dados experimentais, $w$ é a fração mássica, $M$ e $N$ são o número de LAs e componentes, respectivamente, e $I$ e $I I$ se referem as duas fases líquidas em equilíbrio. 


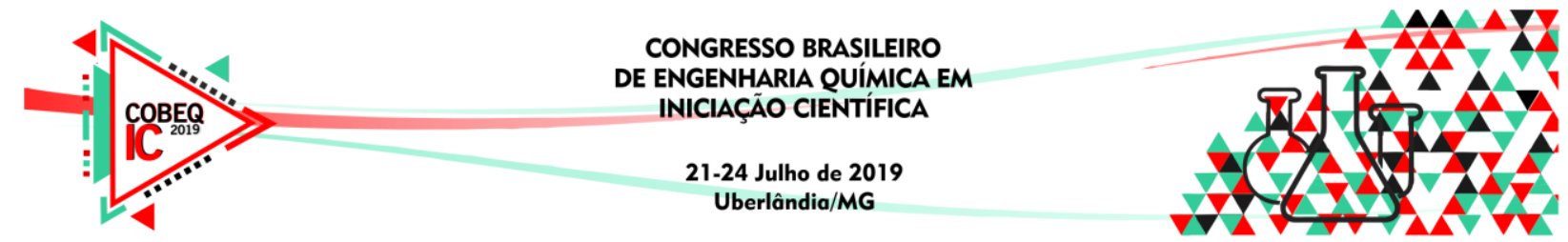

\section{RESULTADOS E DISCUSSÃO}

As curvas binodais e as linhas de amarração dos sistemas $\mathrm{HDEAPr}+\mathrm{H}_{2} \mathrm{O}+$ Acetona e HEAPr $+\mathrm{H}_{2} \mathrm{O}+$ Acetona a $20^{\circ} \mathrm{C}$ e pressão atmosférica $(93,4 \mathrm{kPa})$, obtidas pelo método do ponto de névoa e pelo método gravimétrico, respectivamente, estão apresentadas nas Figuras 1 e 2 .

Figura 1. (A) Curva binodal e (B) linhas de amarração para o sistema $\mathrm{HDEAPr}+\mathrm{H}_{2} \mathrm{O}+$ Acetona a $20^{\circ} \mathrm{C}$.
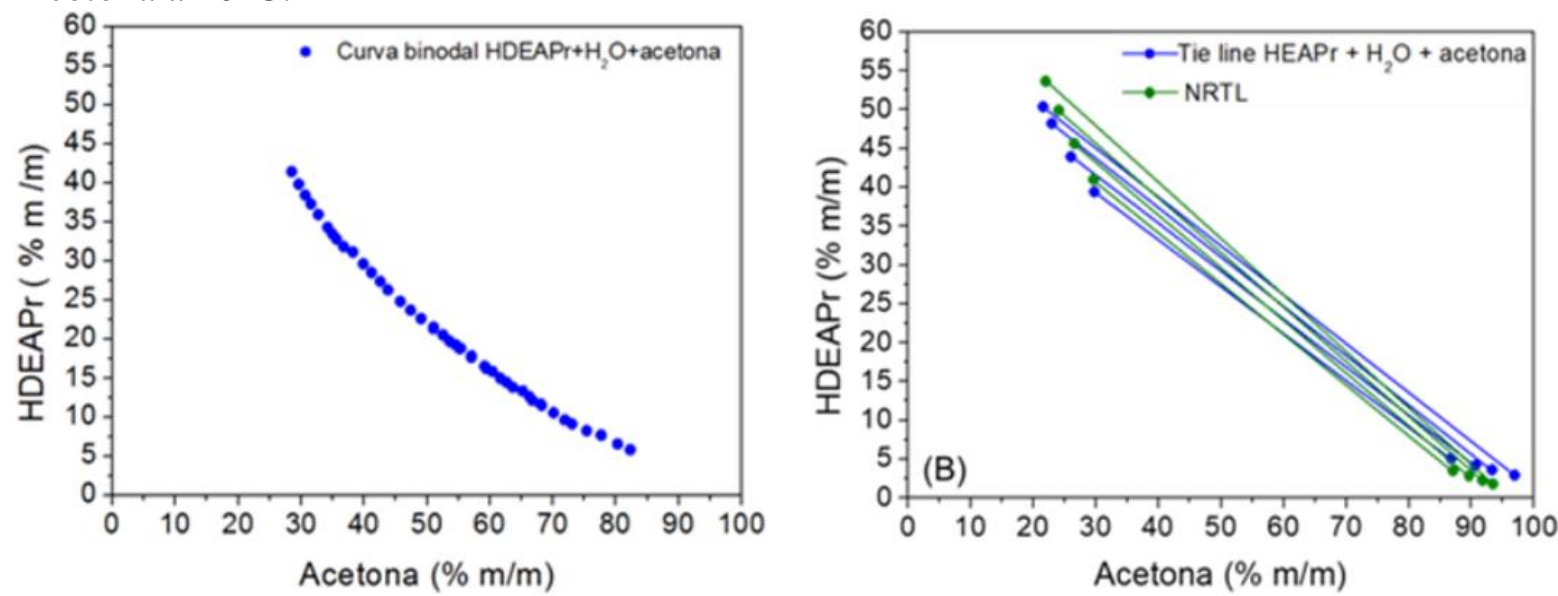

Figura 2. (A) Curva binodal e (B) linhas de amarração para o sistema $\mathrm{HEAPr}+\mathrm{H}_{2} \mathrm{O}+$ Acetona a $20^{\circ} \mathrm{C}$.
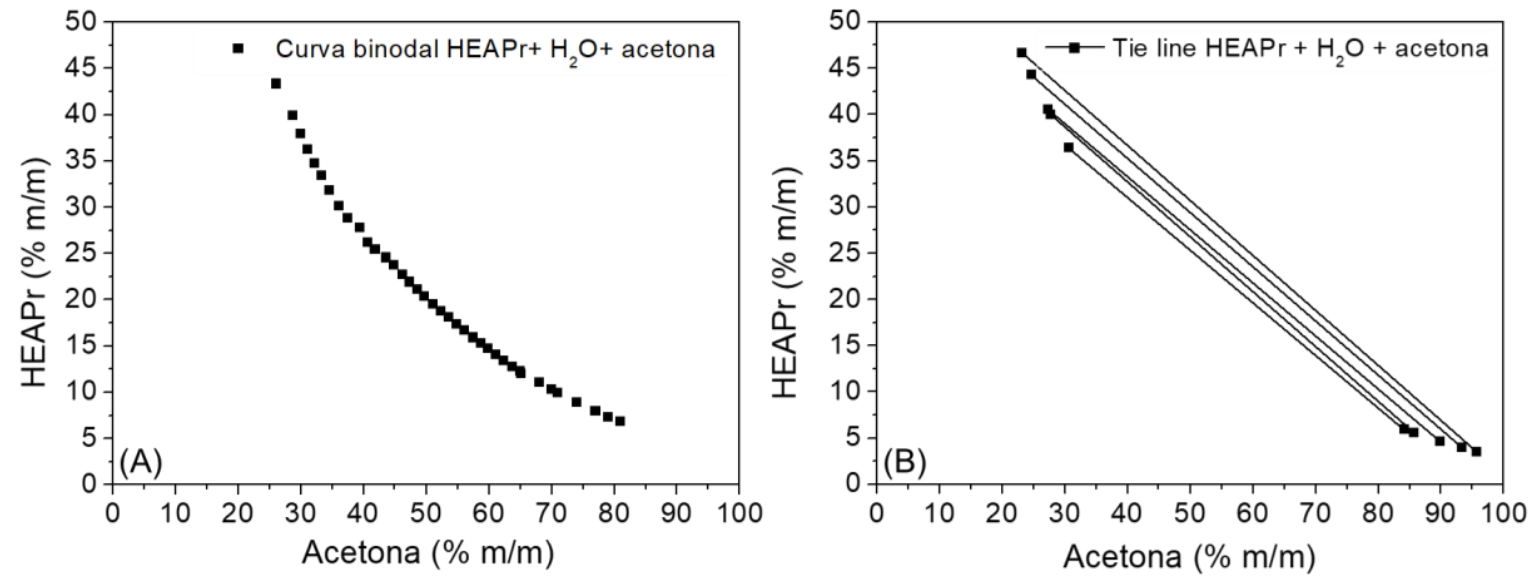

As composições de cada fase dos sistemas, bem como a composição global utilizada para a construção das linhas de amarração estão apresentadas nas Tabelas 1 e 2.

Tabela 1 - Dados experimentais de equilíbrio líquido líquido para o sistema $\mathrm{HDEAPr}+\mathrm{H}_{2} \mathrm{O}+$ acetona a $20^{\circ} \mathrm{C}$ 


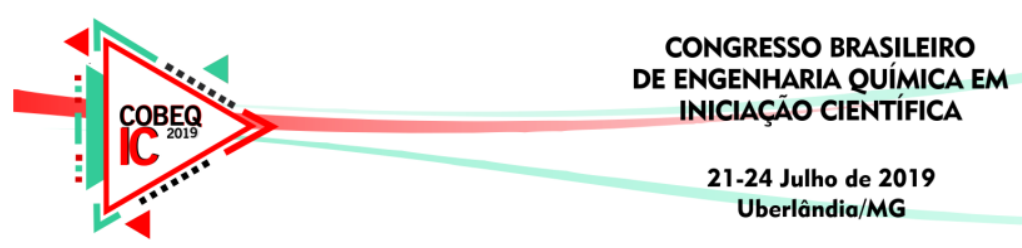

\begin{tabular}{|c|c|c|c|c|c|c|c|c|c|c|}
\hline & \multicolumn{3}{|c|}{ Composição global $(\%$ w) } & \multicolumn{3}{|c|}{ Rafinado $(\%)$} & \multicolumn{3}{c|}{ Extrato $(\% w)$} & \\
\hline \hline LA & Acetona & LIP & Água & Acetona & LIP & Água & Acetona & LIP & Água & ILA \\
\hline 1 & 50,10 & 29,12 & 20,79 & 90,63 & 4,10 & 5,27 & 26,14 & 43,90 & 29,96 & $-1,612$ \\
\hline 2 & 47,40 & 27,60 & 25,01 & 81,28 & 6,58 & 12,14 & 31,64 & 37,37 & 30,99 & $-1,656$ \\
\hline 3 & 48,48 & 28,14 & 23,39 & 86,74 & 5,03 & 8,23 & 29,81 & 39,40 & 30,78 & $-1,574$ \\
\hline 4 & 51,64 & 30,02 & 18,34 & 93,34 & 3,53 & 3,13 & 23,08 & 48,16 & 28,76 & $-1,587$ \\
\hline 5 & 53,05 & 30,53 & 16,42 & 96,95 & 2,87 & 0,19 & 21,68 & 50,29 & 28,02 & $-1,620$ \\
\hline
\end{tabular}

Tabela 2 - Dados experimentais de equilíbrio líquido líquido para o sisteman $\mathrm{HEAPr}+\mathrm{H}_{2} \mathrm{O}+$ acetona a $20^{\circ} \mathrm{C}$

\begin{tabular}{|c|c|c|c|c|c|c|c|c|c|c|}
\hline & \multicolumn{3}{|c|}{ Composição global $(\% w)$} & \multicolumn{3}{|c|}{ Rafinado $(\% w)$} & \multicolumn{3}{c|}{ Extrato $(\% w)$} & \\
\hline \hline LA & Acetona & LIP & Água & Acetona & LIP & Água & Acetona & LIP & Água & ILA \\
\hline 1 & 36,35 & 33,15 & 30,49 & 84,16 & 5,96 & 9,89 & 30,68 & 36,38 & 32,94 & $-1,757$ \\
\hline 2 & 37,12 & 34,42 & 28,46 & 85,64 & 5,60 & 8,76 & 27,76 & 39,98 & 32,26 & $-1,683$ \\
\hline 3 & 38,05 & 34,39 & 27,57 & 89,94 & 4,64 & 5,42 & 27,35 & 40,52 & 32,13 & $-1,744$ \\
\hline 4 & 40,29 & 36,48 & 23,23 & 93,30 & 3,98 & 2,73 & 24,71 & 44,27 & 31,03 & $-1,702$ \\
\hline 5 & 42,84 & 33,62 & 23,55 & 95,65 & 3,56 & 0,79 & 23,17 & 46,66 & 30,16 & $-1,681$ \\
\hline
\end{tabular}

As duas curvas binodais construídas foram modeladas matematicamente de acordo com a equação 1 e os parâmetros obtidos são apresentados na Tabela 3. Eles comprovam que as curvas binodais de ambos os sistemas apresentam um comportamento próximo, apesar da região bifásica do HEAPr ser ligeiramente maior que a do HDEAPr, o que talvez ocorra, pois o HDEAPr possui um grupo hidroxila a mais, promovendo uma interação mais forte com a água.

Além disso, a massa do extrato é maior que a massa do rafinado $\mathrm{E}$, analisando as Tabelas 1 e 2 percebe-se que o componente presente em maior quantidade (\% $w)$ no extrato foi o líquido iônico; enquanto que no rafinado, o componente presente em maior quantidade $(\% w)$ foi a acetona.

O coeficiente de correlação das duas curvas binodais em relação ao modelo de Merchuck foi maior que 0,99 sendo possível afirmar que o modelo de Merchuck se ajustou bem aos dados experimentais determinados. Já o modelo NRTL foi ajustado às linhas de amarração do sistema HDEAPr + água + acetona com desvio médio (RMSD) de 2,07 \%. Os parâmetros resultantes desse ajuste são apresentados na Tabela 4.

Tabela 3 - Parâmetros de Merchuck obtidos para as curvas bimodais dos sistemas HDEAPr+ água+ acetona e HEAPr + água+ acetona e coeficiente de correlação $\left(\mathrm{R}^{2}\right)$.

\begin{tabular}{|c|c|c|c|c|}
\hline Sistema & $\mathrm{A}$ & $\mathrm{B}$ & $\mathrm{C}$ & $\mathrm{R}^{2}$ \\
\hline \hline HDEAPr+água+ acetona & 180,47 & $-0,27$ & $1,62 \mathrm{E}-06$ & 0,999 \\
\hline HEAPr+ água + acetona & 217,87 & $-0,32$ & $1,16 \mathrm{E}-06$ & 0,997 \\
\hline
\end{tabular}




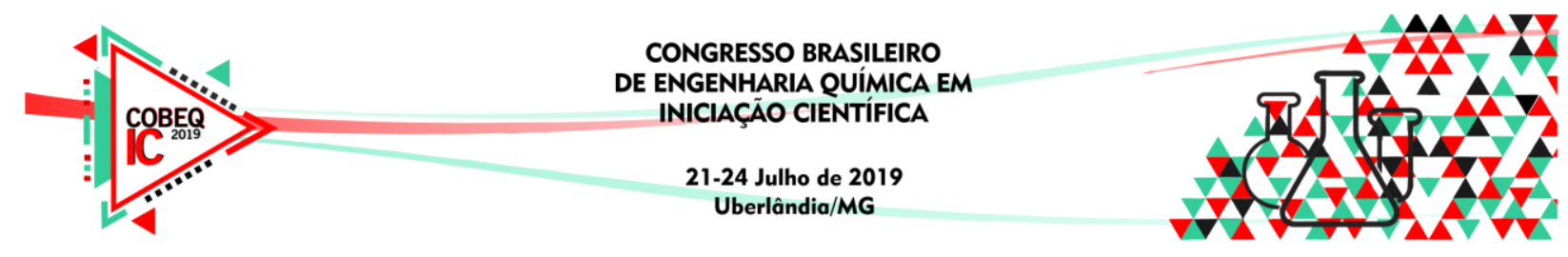

Tabela 4 - Parâmetros determinados através do modelo NRTL para o sistema HDEAPr+ águat acetona a $20^{\circ} \mathrm{C}$.

\begin{tabular}{|c|c|c|}
\hline $\mathrm{A}_{\mathrm{ij}}\left(\mathrm{J} \cdot \mathrm{mol}^{-1}\right)$ & $\mathrm{A}_{\mathrm{ji}}\left(\mathrm{J} \cdot \mathrm{mol}^{-1}\right)$ & $\alpha_{\mathrm{ij}}$ \\
\hline \hline 3216,35404 & 2973,169 & 0,466 \\
\hline 52,7140856 & 4053,906 & 0,322 \\
\hline$-6365,11526$ & $-12238,208$ & 0,236 \\
\hline
\end{tabular}

\section{CONCLUSÕES}

Ambos os sistemas estudados (HDEAPr ou HEAPr) + acetona + água apresentaram comportamento parecido em relação ao equilíbrio em fase líquida. Para cada sistema, foram construídas curvas binodais, às quais o modelo de Merchuck ajustou-se bem, e linhas de amarração, às quais foi ajustado com sucesso o modelo NRTL. Identificou-se que a fase de fundo, o extrato, é rica em líquido iônico e a fase de topo, o rafinado, em acetona. Desta forma, um soluto com afinidades diferentes pela acetona e pelo LI pode ser separado aplicando estes ATPSs, isso é o que será feito na próxima etapa do trabalho com o objetivo de separar algumas biomoléculas.

\section{REFERÊNCIAS BIBLIOGRÁFICAS}

ÀlVAREZ, V. H.; MATTEDI, S.; MARTIN-PASTORD, M.; AZNAR, M.; IGLESIAS, M. Synthesis and thermophysical properties of two new protic long-chain ionic liquids with the oleate anion. Fluid Phase Equilibria. v. 299, p. 42-50, 2010.

EARLE M. J.; SEDDON K. R. Ionic Liquids. Green solvents for the future. Pure Appl. Chem., v. 72, p. 1391-1398, 2000.

KAUL, R. H. Aqueous Two-Phase Systems, Methods and Protocols. New Jersey: Humana Press, 2000.

MACFARLANE, D. R.; SEDDON, K. R. Ionic liquids - Progress on the fundamental issues. Aust. Journal Chem., v. 60, p. 3-5, 2007.

MERCHUK, J. C.; ANDREWS, B. A.; ASENJO, J. A. Aqueous two-phase systems for protein separation. Studies on phase inversion. J. Chromatogr, v.711, p.285-293, 1998.

MIRJARIFARI A.; PHAM, L. N.; MCCABE, J. R.; MOBARREZ, N.; SALTER, E. A.; WIERZBICKI, A.; WEST, K. N.; SYKORA, R. E.; DAVIS JR., J. H. Building a bridge between aprotic and protic ionic liquids. Royal Society of Chemistry, v. 3, p. 337-340, 2013.

NAGANAGOUDA, K.; MULIMANI, V. H. Aqueous two-phase extraction (ATPE): an attractive and economically viable technology for downstream processing of Aspergillus oryzae $\alpha$-galactosidase. Process Biochem, v.43, p.1293-1299, 2008. 


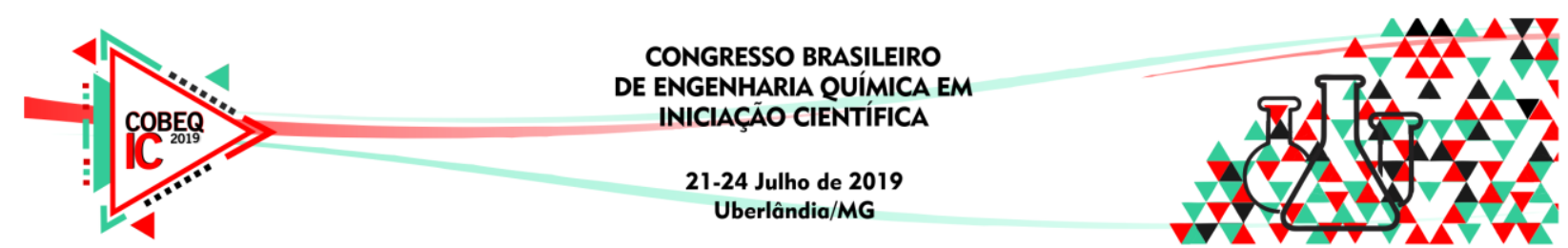

NELDER, J. A.; MEAD, R. A Simplex method for function minimization. Comput. J., v.7, p.308-313, 1965.

STRAGEVITCH, L.; D’ÁVILA, S. G. Application of a generalized maximum likelihood method in the reduction of multicomponent liquid-liquid equilibrium data. Braz. $J$. Chem. Eng., v.14, 1997. 